Corrigendum

\title{
Corrigendum to "Structure, folding and stability of a minimal homologue from Anemonia sulcata of the sea anemone potassium channel blocker ShK" [Peptides 99 (2018) 169-178]
}

Bankala Krishnarjuna $^{a}$, Christopher A. MacRaild ${ }^{\mathrm{a}}$, Punnepalli Sunanda ${ }^{\mathrm{b}}$, Rodrigo A.V. Morales ${ }^{\mathrm{a}}$, Steve Peigneur ${ }^{\mathrm{c}}$, Jason Macrander ${ }^{\mathrm{d}, \mathrm{e}}$, Heidi H. Yu ${ }^{\mathrm{f}}$, Marymegan Daly ${ }^{\mathrm{d}}$, Srinivasarao Raghothama ${ }^{\mathrm{b}}$, Vikas Dhawan $^{g}$, Satendra Chauhan ${ }^{g}$, Jan Tytgat ${ }^{c}$, Michael W. Pennington ${ }^{g}$, Raymond S. Norton ${ }^{\mathrm{a}, *}$

${ }^{a}$ Medicinal Chemistry, Monash Institute of Pharmaceutical Sciences, Monash University, 381 Royal Parade,Parkville, VIC 3052, Australia

${ }^{\mathrm{b}}$ NMR Research Centre, Indian Institute of Science, Bangalore 560012, India

${ }^{\mathrm{c}}$ Toxicology and Pharmacology, University of Leuven, O\&N 2, Herestraat 49, P.O. Box 922, 3000, Leuven, Belgium

d Department of Evolution, Ecology, and Organismal Biology, Ohio State University, 1315 Kinnear Rd, Columbus, OH 43212, USA

e Department of Biology, University of North Carolina at Charlotte, 9201 University City Blvd, Charlotte, NC 28223, USA

${ }^{\mathrm{f}}$ Infection and Immunity Program, Monash Biomedicine Discovery Institute and Department of Microbiology, Monash University, VIC 3800, Australia

${ }^{g}$ Peptides International, Louisville, Kentucky 40299, USA

The authors regret that

Present appearance

[72] B. Wu, B.F. Wu, Y.J. Feng, J. Tao, Y.H. Ji, Mapping the interaction anatomy of

BmP02 on $\mathrm{K}_{\mathrm{V}} 1.3$ channel, 6 (2016) 29431.
After including journal name

[72] B. Wu, B.F. Wu, Y.J. Feng, J. Tao, Y.H. Ji, Mapping the interaction anatomy of

BmP02 on K 1.3 channel, Sci. Rep. 6 (2016) 29431.

The authors would like to apologise for any inconvenience caused.

\footnotetext{
DOI of original article: http://dx.doi.org/10.1016/j.peptides.2017.10.001

* Corresponding author.

E-mail address: ray.norton@monash.edu (R.S. Norton).
} 